\title{
Individual Placement and Support: Penetration and New Populations
}

\author{
Robert E. Drake ${ }^{1} \cdot$ Gary R. Bond $^{1}$
}

Published online: 5 April 2017

(C) Springer Science+Business Media New York 2017

Individual Placement and Support (IPS) began in rural New Hampshire in the early 1990s as an attempt to help people with serious mental disorders find and succeed in competitive employment by combining approaches from assertive community treatment and supported employment (Becker and Drake 1993). An initial quasi-experimental study (Drake et al. 1994), followed by a randomized controlled trial (Drake et al. 1996), validated the model. Over two decades since those initial studies, mental health and employment leaders have refined, studied, and disseminated IPS around the world (Bond et al. 2012; Drake et al. 2012; Mueser et al. 2016). Two dozen randomized controlled studies as well as many other qualitative and quantitative studies have helped not only to validate IPS as an evidence-based practice but also to define target populations, mechanisms, implementation procedures, outcomes, and costs. An international IPS Employment Center now provides education, training, outcome data management, technical assistance, and collaborative research through an extensive learning community, which was started at Dartmouth College by Johnson \& Johnson philanthropy and now resides at the Rockville Institute of the Westat Corporation (http://www.ipsworks.org).

This special section addresses two topics: the spread of IPS for adults with serious mental disorders in the U.S. and the movement to adopt IPS services for new populations.

Robert E. Drake

robertdrake@westat.com

Gary R. Bond

garybond@westat.com

1 The IPS Employment Center, The Rockville Institute, Westat, Rivermill Commercial Center, 85 Mechanic Street, Suite C3-1, Mailbox A4, Lebanon, NH 03766, USA
As the enclosed papers attest, each topic has received considerable attention in the past 5 years.

\section{Spread of IPS in the U.S.}

Despite what appears to be enormous progress, administrative and financing barriers have impeded widespread adoption of IPS. The latest data from the Substance Abuse and Mental Health Services Administration in fact show that only $2 \%$ of adults with serious mental disorders in mental health centers in the U.S. receive IPS (Bruns et al. 2016). Compared with research showing that about $70 \%$ of the same group want competitive jobs, the $2 \%$ figure indicates minimal penetration (Drake et al. 2016). IPS has also spread in many high-income countries around the world, but to our knowledge penetration data are not available.

The first four papers in this special section address dissemination, implementation, and sustainment of IPS services for adults with serious mental disorders. Annalee Johnson-Kwochka and colleagues report on a national survey of IPS prevalence and quality, showing widespread adoption (over 500 programs) and great variance across states. Using qualitative methods, Valerie Noel and colleagues describe the barriers and facilitators to sustaining IPS for local programs within the IPS learning community, confirming that leadership and financing are key factors. Gary Bond and colleagues report on the different strategies used by state mental health and vocational rehabilitation authorities, in the important context of participating in a national learning community. Mustafa Karakas and colleagues update efforts at the federal level to develop funding mechanisms to facilitate the spread of IPS services, with an emphasis on Medicaid waivers and options. 
Together these four papers provide a broad overview about the spread of IPS nationwide and about the challenges and successes in its implementation and sustainment. Surprisingly, such information is rarely available for other evidence-based practices. While mental health research has established the effectiveness of numerous interventions, often under a wide range of conditions, researchers have neither examined the spread of these practices, nor studied the factors influencing the adoption, spread, and sustainment of different practices. Aside from SAMHSA's annual state block grant surveys, we know little about the uptake and continued provision of evidencebased practices, except that access continues to be poor. Thanks to this set of four studies, along with other recent IPS papers, we know more about implementation of IPS than we do about most other psychiatric rehabilitation services for people with serious mental illness.

\section{Other Populations}

The extensive and rigorous research on IPS for adults with serious mental disorders stands in marked contrast with the lack of rigorous empirical research on vocational services for other populations. Consequently, several investigators have begun to explore the use of IPS for other disability groups. They have consistently found that IPS may be a relatively inexpensive way to help many people in these populations to achieve employment success. The second group of four studies in this special section addresses these efforts.

Justin Metcalfe and colleagues examine a large study of IPS for Social Security Disability Insurance beneficiaries with psychiatric impairments, a group that differs slightly from typical community mental health participants, most of whom are Supplemental Security Income beneficiaries, in previous IPS studies. Nevertheless, the findings are mostly similar to those from other IPS studies. Valerie Noel and colleagues describe a project to implement IPS services for young adults with developmental and psychiatric disabilities, many in or destined for sheltered workshops. The barriers and facilitators for developmental disabilities programs differ in important ways from those experienced by mental health programs. Jen McLaren and colleagues describe a pilot study of IPS targeting young adults with autism spectrum disorders and associated mental health issues. The results are exciting but quite preliminary. Carrie Lones and colleagues present another pilot study of IPS services, in this case for people with opioid addiction in methadone maintenance programs. This small randomized controlled trial shows promising outcomes and supports a much larger experiment.

Following the eight papers, two experts from outside of the IPS Employment Center and outside the U.S. offer their perspectives on the papers and ideas for future research.

\section{Conclusions}

We are delighted to present this special section and appreciate the excellent work of the researchers, reviewers, and commentators. Our goal, as always, is to ensure that more people receive needed help in finding satisfying, meaningful, and rewarding jobs. Employment represents opportunity, identity, and human capital for all people. For those with special challenges, it also represents social justice and human rights, which should motivate all of us.

\section{Compliance with Ethical Standards}

Conflict of interest The authors have no conflicts to declare.

Ethical Approval This paper is an introduction to a special section; it does not involve human subjects and does not report research.

\section{References}

Becker, D. R., \& Drake, R. E. (1993). A working life: The Individual Placement and Support (IPS) program. Concord: New Hampshire-Dartmouth Psychiatric Research Center.

Bond, G. R., Drake, R. E., \& Becker, D. R. (2012). Generalizability of the individual placement and support (IPS) model of supported employment outside the US. World Psychiatry, 11, 32-39.

Bruns, E. J., Kerns, S. E., Pullmann, M. D., Hensley, S. W., Lutterman, T., \& Hoagwood, K. E. (2016). Research, data, and evidence-based treatment use in state behavioral health systems, 2001-2012. Psychiatric Services, 67, 496-503.

Drake, R. E., Becker, D. R., Biesanz, J. C., Torrey, W. C., McHugo, G. J., \& Wyzik, P. F. (1994). Rehabilitation day treatment vs. supported employment: I. Vocational outcomes. Community Mental Health Journal, 30, 519-532.

Drake, R. E., Bond, G. R., \& Becker, D. R. (2012). Individual placement and support: An evidence-based approach to supported employment. New York: Oxford University Press.

Drake, R. E., Bond, G. R., Goldman, H. H., Hogan, M. F., \& Karakus, M. (2016). Individual placement and support services boost employment for people with serious mental illness, but funding is lacking. Health Affairs, 35, 1098-1105.

Drake, R. E., McHugo, G. J., Becker, D. R., Anthony, W. A., \& Clark, R. E. (1996). The New Hampshire study of supported employment for people with severe mental illness: Vocational outcomes. Journal of Consulting and Clinical Psychology, 64, 391-399.

Mueser, K. T., Drake, R. E., \& Bond, G. R. (2016). Recent advances in supported employment for people with serious mental illness. Current Opinion in Psychiatry, 29, 196-201. 